\title{
New records, and the first description of a female, for Psychoda simillima (Diptera, Psychodidae) in southern South America
}

\author{
Danilo Cordeiro ${ }^{1}$, Guillermo Omad ${ }^{2}$, Freddy Bravo $^{3}$ \& Claudio J. B. de Carvalho ${ }^{1}$ \\ 1. Programa de Pós-graduação em Entomologia, Departamento de Zoologia, Universidade Federal do Paraná, UFPR. Caixa Postal 19020, 81531-980, Curitiba, PR, Brazil. (d.pacheco.c@gmail.com; \\ cjbcarva@ufpr.br) \\ 2. Laboratorio de Investigaciones en Ecología y Sistemática Animal, Universidad Nacional de la Patagonia San Juan Bosco, Sarmiento 849, Casilla Postal 9200, Sede Esquel, Chubut, Argentina. \\ (guillermoomad178@hotmail.com) \\ 3. Departamento de Ciências Biológicas, Universidade Estadual de Feira de Santana, Av. Universitária s/n, 44031-460, Feira de Santana, BA, Brazil. (fbravo@uefs.br)
}

ABSTRACT. Based on male and female, Psychoda simillima Tonnoir, 1929 is redescribed, with a discussion of generic and subgeneric classifications. This is the first record for Chile as well as the first description of a female for this species.

KEYWORDS. Argentina, Chile, Psychodini.

RESUMO. Com base em machos e fêmeas, Psychoda simillima Tonnoir, 1929 é redescrita, junto com uma discussão sobre a classificação genérica e subgenérica dessa espécie. Este é o primeiro registro dessa espécie para o Chile, assim como a primeira vez que a fêmea é descrita.

PALAVRAS-CHAVE. Argentina, Chile, Psychodini.

When described, Psychoda simillima Tonnoir, 1929 was placed in the subgenus Threticus Eaton, 1904 (TonNoIR, 1929). The genus Threticus was proposed by EATON (1904) based on the difference in the structure of the male genitalia, the cerci [cercopods on TonNOIR (1929)] being much longer than the epandrium (ninth tergite) in Threticus and about equal size in Psychoda Latreille, 1796. However, Threticus, considered a subgenus of Psychoda by TonNoIR (1929), was reinstated as a genus by QUATE (1959), who based this mainly on the shape of the ascoids (one superior and one inferior branch in Threticus and Y-shaped in Psychoda), and the mouthparts (bulbous without apical teeth in Threticus and flattened with apical teeth in Psychoda).

Within Psychoda sensu QuATE (1959) the shape of the cercus was used again in a genus-level classification by JeŽEK $(1983,1984)$. He used the short cercus (with posterior third bare), and the antenna with 14 flagellomeres (the last three of which are separate and subequal in size), as diagnostic characters that separate the genus Psychodocha Ježek, 1984 from all other genera. The putative Psychoda simillima fit within Psychodocha by that proposal, yet it was not included in the list provided by JEŽEK (1983), when he described the genus. Psychodocha was later considered to be a subgenus (Bravo et al., 2006), due to problems with the Ježek classification for Neotropical fauna. This subgeneric classification was considered but not strictly used by CORDEIRO et al. (2011) due to variation in many characters in the neotropics. However, the neotropical fauna are not unique in divergent morphologies. For example, two species (Psychoda martini Hogue, 1970 from Kenya and Psychoda aponesos Quate, 1959 from New Guinea) have apical flagellomeres as described for Psychodocha, but also have long cerci. Apically bare short cerci are found in species belonging to other subgenera, such as Psychoda albescens Quate \& Quate, 1967 (from New Guinea), which was transferred to Logima Eaton, 1904 by JEŽEK (1984).

Psychoda simillima shares some characters with other species of the subgenus Psychodocha that are absent, or very rare, in other Psychoda: a relatively large vertex (longer than the width of the eye bridge); a vertex hair patch that extends laterally to the occiput; a relatively long palpus, long tarsomeres (mainly the first), and short and truncate Sc. Additional genera of the Psychodini sensu QuATE (1959) also share some of these characteristics and are considered by many to be related to Psychoda, such as Threticus, Neomaruina Vaillant, 1963 and Philosepedon Eaton, 1904. Interestingly, P. simillima lacks the frontoclypeal suture that is found in all species (that we have seen) of the subgenus Psychodocha with the exception of P. itoco Tokunaga \& Komyo, 1954 (from Japan). The lack of the additional anterior sclerite of the pteropleurite, the large trapezoidal pteropleurite completely restricted by sutures (JEŽEK, 1983), the flattened labellum with only apical teeth and the second costal node are characteristics that support the inclusion of $P$. simillima into Psychoda sensu Quate. A phylogenetic analysis of this group is needed to better understand the evolution of these characters. Here, we provide a more complete description for this species, and include the female for the first time and report new geographic records.

\section{MATERIAL AND METHODS}

We follow terminology of Cumming \& Wood (2009), with the specific terms "teeth", on the labellum, and "genital digit" following Quate (1955), and "genital chamber" following QUATE \& BROWN(2004). For thoracic chaetotaxy we follow GaLATI (2003). The specimens are 
deposited at Universidad Nacional de la Patagonia San Juan Bosco, Laboratorio de Investigaciones en Ecología y Sistemática Animal (LIESA) and Natural History Museum, London (BMNH).

\section{Psychoda simillima Tonnoir, 1929}

(Figs 1-15)

Psychoda simillima TonNOIR, 1929:8.

Examined material. ARGENTINA, Chubut (Nameless stream, $\left.42^{\circ} 29^{\prime} 44^{\prime \prime} \mathrm{S}-71^{\circ} 23^{\prime} 21^{\prime \prime} \mathrm{W}\right), 3{ }^{\wedge}$, 5 9 , 15.X-8.XI.2010, Malaise trap, G. H. Omad leg. (LIESA); same locality, $2{ }^{\top}$,, , 20.IX.2010, hand net, G. H. Omad leg. (LIESA); CHILE, Última Esperanza, Pena. Muñoz Gamero (HM3, 20-40ft), 2ð, 3 , , 27.XII.1958, Nothofagus antarctica (BMNH(E) \#950432-950436).

Distribution. Southwest Argentina (Bariloche, Neuquén Province; west of Chubut Province, new record) and South Chile (Peninsula Muñoz Gamero, new record)

Diagnosis. Antenna with 14 flagellomeres, last three smaller and separated; frons hair patch not extending dorsally between eye bridge; male cerci short; paramere longer than aedeagus, bent apically; basal band of female subgenital plate divided medially and inflated, genital digit subconical, with 2 spines at apex, and a pair of lateral pilose rounded structures.

Redescription. Head: vertex, frons and clypeus pilose (Fig. 1); frons hair patch not extending between eye bridge; eye bridge with 4 facet rows, separated by $0.7-1.0$ facet diameters; vertex hair patch slightly divided on medial line, extending laterally to the occiput (Fig. 2); 6 supra-ocular setae, 3-4 occipital strong alveoli higher than usual in Psychoda, close to the supra-ocular setae; interocular suture absent; clypeus with 1-3 conspicuous lateral alveoli (but which are generally similar to the other alveoli of the clypeus); frontoclypeal suture absent; antenna with scape cylindrical, 1.7 the length of the subspherical pedicel (Fig. 3), and with 14 flagellomeres, 12-14 reduced, subspherical and separated (Fig. 4), eleventh with distinct though very small neck; ascoids form Y; palpal formula 1.0:1.25-1.42:1.25-1.45:1.6-1.7 (Fig. 5); labellum with 6 apical teeth (5 long, 1 short) and 2 lateral setae (Fig. 6). Thorax (Fig. 7): pre-sutural setae join supralar setae in a small area; anepisternal setae forming 3 poorly delimited patches, more easily distinguished on males, in which the middle patch has modified alveoli (slightly larger with thinner cuticle at margin) (Fig. 8); anepimeral setae numerous; pteropleurite large, trapezio-retangular; anepisternal suture complete; tranversal suture on upper margin of catespisternum short, but present. Wing (Fig. 9): Second Costal node present; Sc vein short, truncate, not extending beyond line of base of veins Rs, $\mathrm{M}$ and $\mathrm{CuA} ; \mathrm{R}_{1}$ ending at the same level of $\mathrm{CuA}_{2} ; \mathrm{R}_{2}$ and $\mathrm{R}_{3}$ slightly sinuous at apex in some specimens; radial fork apical to medial fork, both complete, $\mathrm{M}_{2}$ weakened at base; $\mathrm{M}_{1+2}$ expanded at base; Costal cell darkened. Legs: tibial subapical setae present in all legs, but not very conspicuous; first tarsomere long, around 2.7 times longer than the second; distitarsus with apical projection, and small lateral projection (Fig. 10); claws strongly angular $\left(90^{\circ}\right)$. Male terminalia: cercus short, around 1.2 times the length of epandrium, conical, with one apical tenaculum and three subapical papillae (Fig. 11); epandrium with one large foramen (Fig. 12); hypandrium expands posteriorly in a V shaped plate, with rounded apex (Fig. 13); gonostylus about 1.3 times the length of gonocoxite, with few small setae sparsely distributed and a clump of four, probably sensorial, papillae at base; gonocoxite apodemes join medially to form a gonocoxal bridge that projects posteriorly as a trilobed assymetrical structure; aedeagus long and slender, slightly curved to the right; aedeagal apodeme around 0.6 times the length of the aedeagus, strongly expanded; paramere very long, towards the left side then curves strongly to right near apex. Female terminalia: subgenital plate bilobed, pilose except on base (Fig. 14); genital digit present, coniform with one apical spine (Fig. 15); basal band of subgenital plate strongly inflated on each side, also forming a strong longitudinal suture on subgenital plate; genital chamber large, well sclerotized, with a long posterior apodeme; cercus long, slender and straight, around 1.3 times the width of female genitalia at base.

Measurements $(\mathrm{mm})$. Males: head length 0.54, head width 0.45 , palpus length $0.43-0.48$, wing length 2.55-2.78, wing width 1.03-1.1; females: head length $0.55-0.61$, head width $0.42-0.49$, palpus length 0.52 0.55 , wing length $3.25-3.49$, wing width 1.29-1.42.

Comments: In contrast to the original description, there are no erect hairs on $R_{1}$ in the specimens we examined, but the shape of male genitalia is a conspicuous diagnostic character for this species. TonNoIr (1929) noted that Psychoda simillima is very similar to Psychoda pseudocompar Tonnoir, 1929 being different only by the structure of male genitalia, which is remarkable for the unusual development of aedeagus and paramere in the former. Psychoda simillima is apparently closely related to the subgenus Psychodocha, but the lack of the clypeal suture causes uncertainty for its classification.

The two males used originally for the description were collected on a window in Bariloche, Argentina. In two other places (Argentina and Chile) we found males (and females) that are identical to the description of TonnorR (1929), except for the erect hairs on $R_{1}$. These females, the first ever found, are clearly associated with the males by all non-genitalia characters. The five specimens collected in Chile (probably collected at Royal Society Expedition to Southern Chile, 195859) were found in Nothofagus antarctica (G. Forster) Oersted forest (as indicated in the specimens labels). 


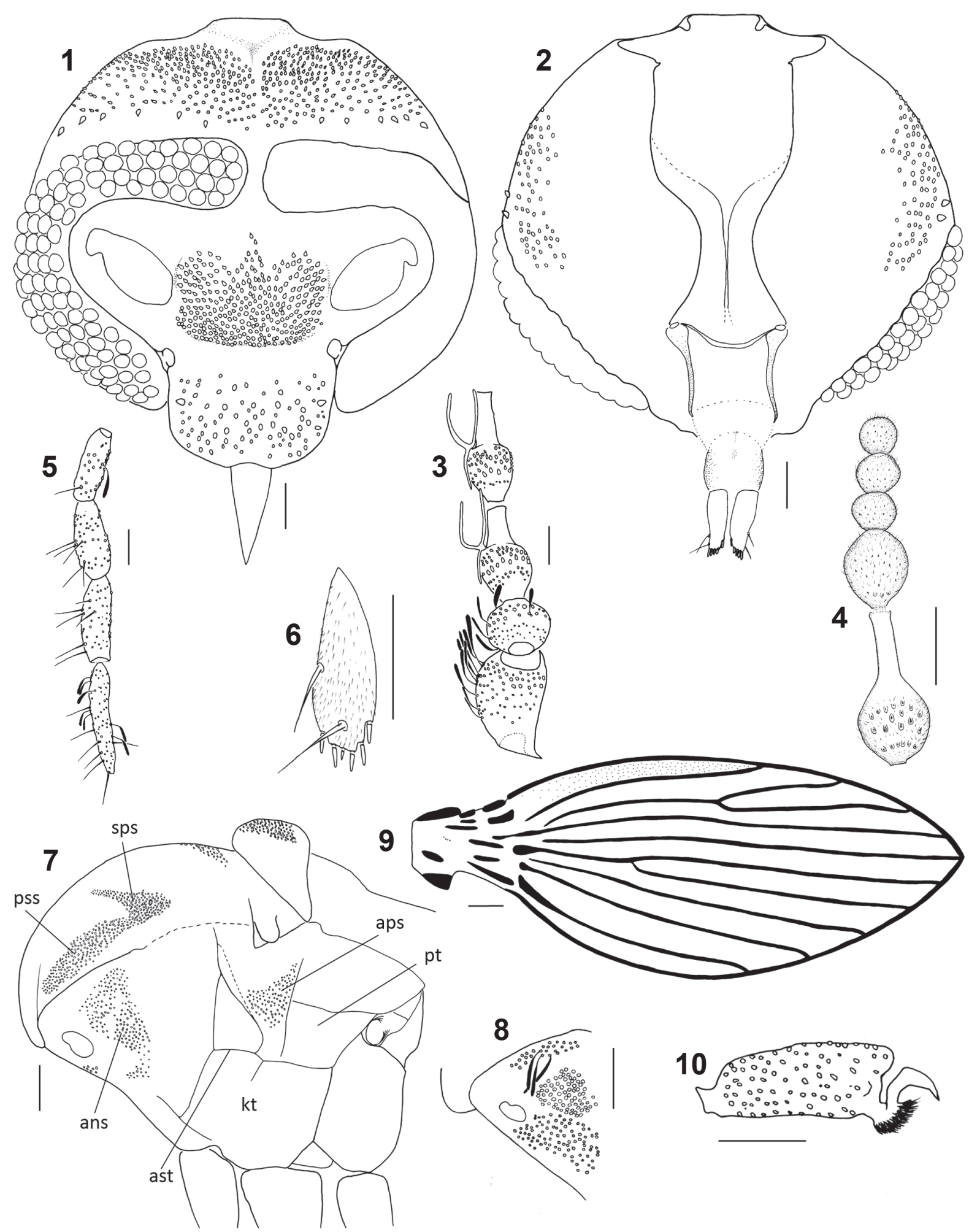

Figs 1-10. Psychoda simillima Tonnoir, 1929: 1-5, 7, 9 female; 6, 8, 10 male. Head: 1, anterior; 2, posterior. Antenna: 3, scape, pedicel and basal flagellomeres; 4, flagellomeres 10-14. 5, Palpus; 6, labellum; 7, thorax, lateral; 8, anepisternal setae of thorax; 9, wing; 10, distitarsus (ans, anepisternal setae; aps, anepimeral setae; ast, anepisternal suture; kt, caterpisternum; pps, pre-sutural setae; pt, pteropleurite; sps, supralar setae). Scales $0.05 \mathrm{~mm}$, except Figs 7, 8, $0.01 \mathrm{~mm}$ and Fig. 9, $0.2 \mathrm{~mm}$. 


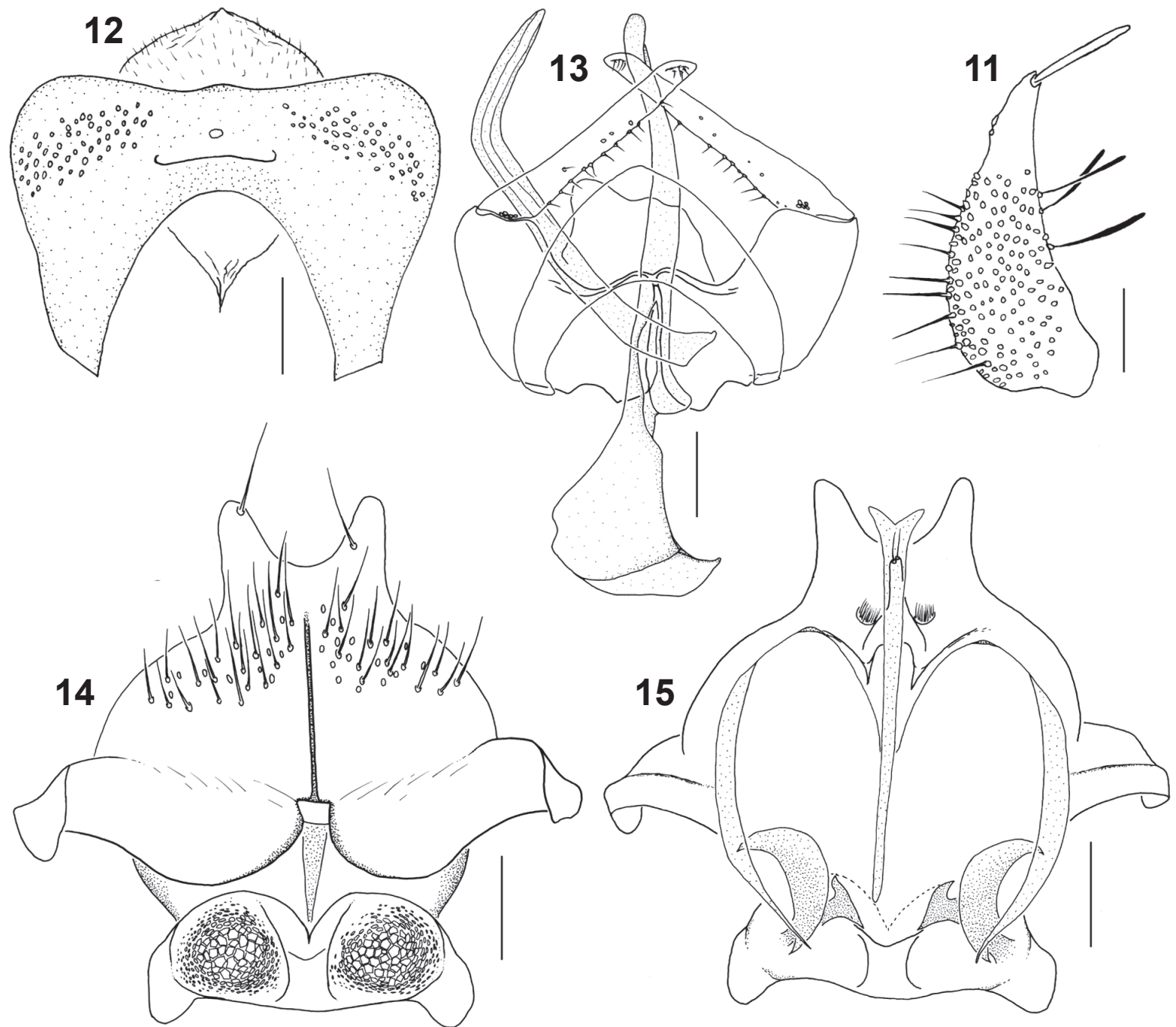

Figs 11-15. Psychoda simillima Tonnoir, 1929: 11-13, male terminalia; 11, cercus; 12, epandrium and sternite 10; 13, dorsal terminalia. Subgenital plate and genital chamber: 14 , dorsal; 15 , ventral. Scales $0.05 \mathrm{~mm}$.

Acknowledgements. We are very thankful to Erica McAlister, for the loan of the specimens from the BMNH. We thank the Conselho Nacional de Desenvolvimento Científico e Tecnológico (CNPq) for the support provided - processes 141146/2009-5 (DC) and 304713/20112 (CJBC). Guillermo Omad is thankful for Consejo Nacional de Investigaciones Científicas y Técnicas (CONICET). And thanks to James J. Roper for the English revision and the reviewers for their useful comments.

\section{REFERENCES}

Bravo, F.; Cordeiro, D. \& Chagas, C. 2006. Two new species and new records of Psychoda Latreille (Diptera, Psychodidae, Psychodinae) from Brazil, with comments on supraspecific classification of the genus and an actualized list of Latin American and Caribbean islands species. Zootaxa 1298:1-15.

Cordeiro, D.; Bravo, F. \& de Carvalho, C. J. B. 2011. Taxonomy of Brazilian Psychoda Latreille, 1796 (Diptera, Psychodidae) with the description of thirteen new species. Zootaxa 3101:1-37.

Cumming, J. M. \& Wood, D. M. 2009. Adult morphology and terminology. In: Brown, B. V.; Borkent, A.; Cumming, J. M.; Wood, D. M.; Woodley, N. E. \& Zumbado, M. A. eds. Manual of Central American Diptera. Ottawa, NRC Research Press, v. 1, p. 9-50.
EAton, A. E. 1904. New genera of European Psychodidae. Entomologist's Monthly Magazine, Ser. 2, 15:55-59.

Galati, E. A. B. 2003. Morfologia e Taxonomia. Classificação de Phlebotominae. In: Rangel, E. F. \& Lainson, R. eds Flebotomíneos do Brasil. Rio de Janeiro, Editora Fiocruz, p. 23 51.

JEŽEK, J. 1983. Intergeneric relationships of selected tribes of the subfamily Psychodinae (Diptera, Psychodidae). Acta Entomologica Musei Nationalis Pragae 41:254-259.

1984. Six new genera of the tribe Psychodini End. (Diptera, Psychodidae). Acta Faunistica Entomologica Musei Nationalis Pragae 17:133-153.

Quate, L. W. 1955. A revision of the Psychodidae (Diptera) in America North of Mexico. University of California Publications in Entomology 10:103-273.

1959. Classification of the Psychodini (Psychodidae: Diptera). Annals of the Entomological Society of America 52:444-451.

Quate, L. W. \& Brown, B. V. 2004. Revision of Neotropical Setomimini (Diptera: Psychodidae: Psychodinae). Contributions in Science, Natural History Museum of Los Angeles County 500:1-117.

TonnoIr, A. L. 1929. Diptera of Patagonia and South Chile, pt. 1. Fascicle I - Psychodidae. London, British Museum (Natural History). 32p. 